\title{
"IT'S AS IF THERE IS NO COUPLE": EXPERIENCES OF LESBIAN WOMEN WITH BREAST CANCER AND THEIR PARTNERS IN HEALTH SERVICES
}

\author{
Carolina de Souza'1, Manoel Antônio dos Santos ${ }^{1}$ \\ ${ }^{1}$ Psychology Department, Ribeirão Preto School of Philosophy, Sciences and Letters, Universidade de São Paulo - Ribeirão \\ Preto (SP), Brazil.
}

The model of a woman expected in health services is as follows: adult, mother, and heterosexual. Any woman who breaks this pattern is invisibilized or goes through services that are not adequate for her particular demands. Most of the time, lesbian women go unnoticed in health services, and the identification of their sexual orientation does not occur directly, in consultations with the women, but by the identification of others of characteristics considered as male gender, such as short hair, masculine way of walking, and type of clothes. Objective: This study aims to understand the meanings attributed by a lesbian couple to the discrimination suffered in health services. Methodology: This is a qualitative, cross-sectional, descriptive, exploratory study that had gender studies as theoretical references. One woman with breast cancer and her partner participated. An in-depth interview was conducted with each of the participants and, subsequently, the data were analyzed and discussed from the perspective of the inductive thematic content analysis. Results: The participants reported more than one experience of discrimination with the health professionals they encountered throughout the cancer treatment: sexist comments, invisibilization, and denial of the relationship of the two as a couple, among others. It can be said that women are taught, since they are born, to be mothers, to take care of others, and to "give pleasure to the other." Thus, the sexuality of women is denied, repressed, and feared. These gaps invisibilize lesbianities within the healthcare system. Conclusion: The findings of this study also allow us to look toward the health issues of lesbian women, whose vulnerabilities are amplified by the need to defend their dissident identities and sexualities when they are in contact with health services. Fighting the inequities experienced by lesbian women in the health sector is a challenge for the effective implementation of health rights, with respect to citizenship and dignity.

Keywords: Homosexuality; Female; Breast Neoplasms; Health Services; Discrimination. 